\title{
-Reviews-
}

\section{Prostatitis : Especially concerning studies of leukocytosis in prostatic fluid and bacterial culture, and daily practice}

\author{
Taiji Nishimura* \\ Department of Urology, Nippon Medical School
}

Key words: prostatitis, macrophages

\section{Introduction}

"Even though prostatitis remains a complex, often puzzling disease, studies during the last decade have clarified many of its features". "Urologists have made great strides in the diagnosis and treatment of prostatitis in the past two decades". These are quotations from Meares ${ }^{1}$ in 1980 and Drach ${ }^{2}$ in 1986, respectively. These writers thought there had been remarkable progress in the 1) etiology, 2) methods of diagnosis, 3) pathophysiology and 4) therapy of prostatitis over the past 10 to 20 years at that time. However, I, as well as many urologists, think there has been no progress at all which is beneficial to patients over the past 3 decades. My reasons are as follows: 1) The etiology of nonbacterial prostatitis (NBP) and prostatodynia, which constitute most cases of prostatitis, is still undetermined; 2) Meares and Stamey ${ }^{3}$ reported a method of diagnosis in bacterial prostatitis and other lower urinary tract infections in 1968. In this method, diagnosis of prostatitis can be made if a larger number of bacteria is found in expressed prostatic secretion (EPS) or voided bladder 3 (VB 3), which is urine obtained after prostatic massage, than in voided bladder 1 (VB 1), which is the first portion of urine upon urination, or voided bladder 2 (VB 2) which is the middle portion of urine upon urination (Fig. 1). However, this was not an original method at all. Bacterial cultures of VB 2 and EPS had already been reported by Ghormley ${ }^{4}$ in 1954 and Stahler ${ }^{5}$ had already reported that EPS can be replaced by VB 3 in 1955 . Guze ${ }^{6}$ reported low num- bers of bacteria' such as $100 / \mathrm{ml}$, can be a cause of urinary tract infection (UTI) when they used urine obtained by suprapubic puncture in 1958 , that is 10 years prior to the presentation of Meares and Stamey $^{3}$, who mentioned the importance of small numbers of bacteria; 3) In 1968, Stamey et al. ${ }^{7}$ reported the antibacterial nature of prostatic fluid in journal of the "Nature", suggesting some special

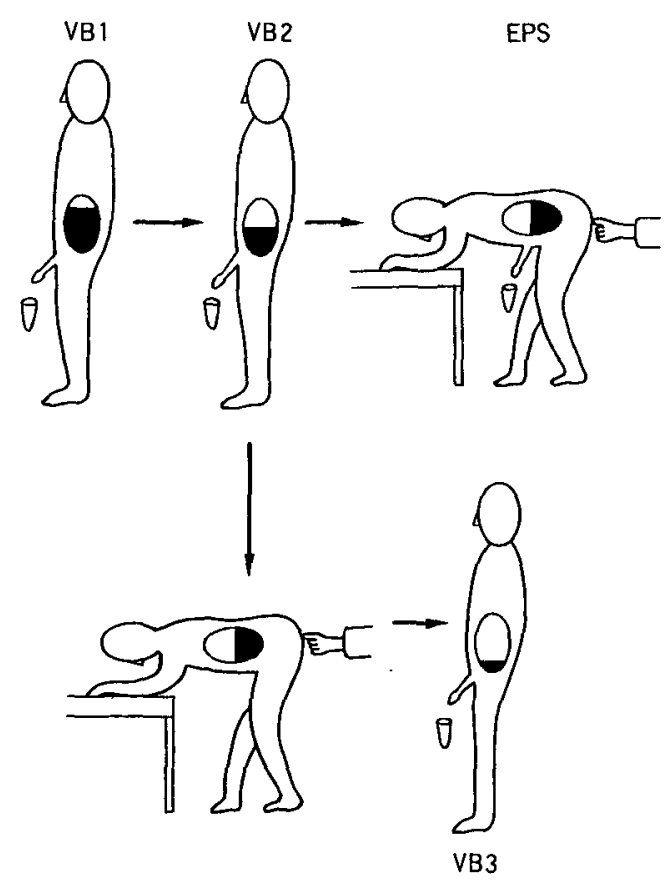

Fig. 1 Method of obtaining four specimens for the diagnosis of prostatitis. EPS: Exressed prostatic secretion, VB1: Voided bladder 1, VB2: Voided bladder 2, VB3: Voided blad$\operatorname{der} 3$. 
protein obtained by Sephadex column filtration would have the antibacterial nature, but ungainly it was found simply to be zinc after 10 years of research. They also reported in $1972^{8}$ that the factors determining the diffusion and concentration of antibiotics across biological membranes are lipid solubility, the degree of ionization in plasma, protein binding, and the molecular radius and shape if small and water soluble for the former, and $\mathrm{pH}$ value and gradient for the latter. As a results of their study, they recommended the use trimethoprim-sulfamethoxazole (TMP-SMX). However, in contrast to their basic research, the clinical usefulness of cefmenoxime and latamoxef in acute bacterial prostatitis (ABP) was reported by Katoh et al. ${ }^{9}$ in 1992, probably because of damage to the biological membrane in inflammation due to infection. Newquinolons are now widely used regardless of Stamey's theory ; 4) Since the etiology of NBP and prostatodynia is undertermined, it is impossible to establish sure treatment at present.

In this paper, I would like to describe the definition, classification, diagnosis and management of prostatitis with as many tables and interesting illustrations as possible to ensure that this paper is easily understood by doctors other than urologists, will attract attention of them and be beneficial for them in daily practice. I would also like to refer to the history of research including some of my own.

\section{Definition of whole prostatitis}

Most papers that have decribed prostatitis did not mention definition of whole prostatitis, and started with the classification of 4 groups of prostatitis from the beginning. If I may dare to describe a definition of prostatitis, "it is a disease with slight to severe symptoms' such as a feeling of residual urine, urethral burning, dysuria, frequency, nocturia, pain or discomfort upon ejaculation, discomfort or pain in the suprapubic, lumbar, perineal, scrotal, inguinal or thigh area, with or without leukocytosis in the prostatic fluid (PF)" (Table 1).

\section{Classification and brief summary of diagnosis and treatment}

The charateristics of the four groups are summar. ized in Table 2.

(1) $\mathrm{ABP}$

Diagnosis: Usually symptoms are severe and very easy to diagnose. However, gross hematuria caused by concurrent cystitis often confuses doctors. Differential diagnosis can easily be performed by noninvasive renal and suprapubic transabdominal bladder ultrasound to exclude urinary tract malignancy or stone disease. Beside the symptoms in Table 1, fever and general malaise are unique in ABP. Urine culture is definitely positive unless antibiotics are given prior to bacterial culture, and the most frequent causative organism is Escherichia coli. Urinalysis shows many white blood cells and/or red blood cells.

Treatment: Patients can be treated on an outpatient basis, but in some institutions all ABP patients are treated on an in-patient basis. This

Table 1 Definition of prostatitis: Disease with the following symptoms with or without leukocytosis in $\mathrm{PF}$

$\begin{array}{ll}\text { feeling of residual urine } & \text { urethral burning } \\ \text { dysuria } & \text { frequency } \\ \text { nocturia } & \text { pain or discomfort upon ejaculation } \\ \text { discomfort or pain on suprapubic, lumbar, perineal, scrotal, inguinal or thigh area }\end{array}$

Table 2 Classification of prostatitis

\begin{tabular}{l|ccc}
\hline & $\begin{array}{c}\text { Excessive WBCs } \\
\text { in EPS }\end{array}$ & $\begin{array}{c}\text { Positive Culture } \\
\text { of EPS }\end{array}$ & Treatment \\
\hline ABP & Yes & Yes & Antibiotics \\
NBP & Yes & Yes & Antibiotics \\
Prostatodynia & Yes & No & $\begin{array}{c}\text { Antibiotics, } \alpha_{1} \text { blocker } \\
\text { Chinese medicine } \\
\text { Thermotherapy }\end{array}$ \\
& No & No & $\begin{array}{c}\text { Antibiotic, } \alpha_{1} \text { blocker } \\
\text { Antispasmodic }\end{array}$ \\
\hline
\end{tabular}


Table 3 Changes in PSA levels in a 62 year- old patient with ABP

\begin{tabular}{lr|ccc}
\hline \multicolumn{2}{c|}{ Date } & $\begin{array}{c}\text { PSA level } \\
\text { (normal level } \\
\text { is 3.6 ng/ml) }\end{array}$ & Leukocytosis in PF & Symptoms \\
\hline Aug. & 8 & 14.0 & severe & severe \\
Sept. & 5 & 3.7 & none & slight \\
Oct. & 3 & 2.6 & none & slight \\
Dec. & 10 & 1.2 & none & very slight \\
\hline
\end{tabular}

Table 4 Representative causative organisms in CBP

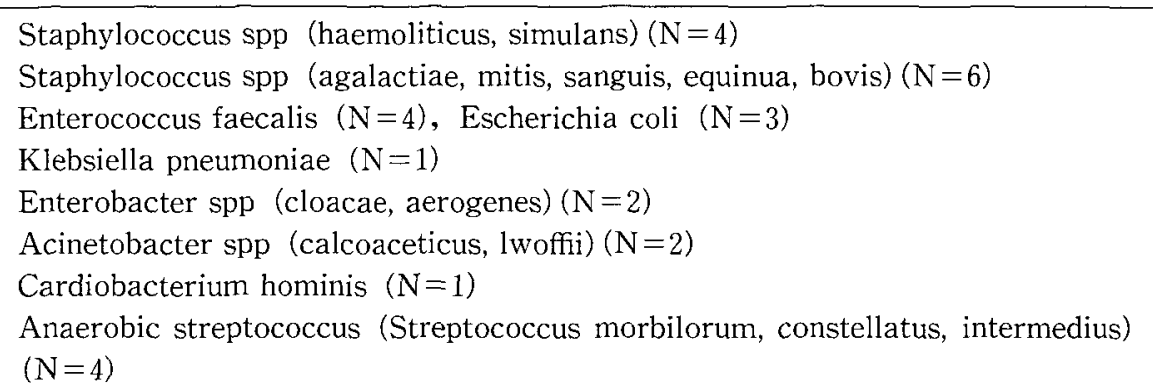

depends more on the policy of the doctor than the severity of the disease. Patients respond well to antibiotics, although symptoms often subside slowly. Therefore it is very important to explain this to the patients so that the patients do not go around other hospitals worrying about the very slow improvement of their symptoms.

Significance of prostate-specific antigen (PSA): It is clinically important and interesting that PSA has definitely increased during ABP since cancer of the prostate recently started increasing in frequency and screening of prostate cancer with PSA level started to be performed in routine health check-ups in Japan. The reason for elevated PSA in ABP would seem to be damage to the barrier between vessels and interstitial tissues or glands with resultant inflow of PSA to the vessels. Therefore, elevation of PSA is also observed upon indwelling of a balloon catheter. The elevation of PSA in ABP returns to a normal level within 14 days $^{10}$. Our data regarding changes in PSA levels in ABP are shown in Table 3.

(2) Chronic bacterial prostatitis (CPB)

Diagnosis: Bacterial cultures must be performed cautiously, to avoid contamination and killing the causative organism. Culture should be performed immediately, without leaving the specimen in an out-patient clinic for hours. CBP is so low in frequency that only 27 cases were collected during a 6-month study in 17 institutions located within Tokyo. The study was carefully performed, avoiding other UTI such as urethritis, cystitis and false positive culture by contamination ${ }^{11}$. The causative organisms are shown in Table 4. The symptoms shown in Table 1 are mild in most cases, though often persistent.

Treatment: Treatment with antibiotics must be continued until the carefully performed bacterial culture becomes negative.

History of bacteriological study: Since the 1940 s, many studies have been performed emphasizing the avoidance of contamination and proving that the organism obtained is the real causative organism. These included the culture of EPS obtained after urethral irrigation ${ }^{12}$, endoscopic sampling of specimens $^{13}$, and bacterial cultures of prostate tissues obtained by needle biopsy ${ }^{14}$.

Pathogenesis of gram positive bacteria: Stamey ${ }^{8}$ denied, but Drach ${ }^{15}$ insisted on the possibility of gram positive bacteria such as Staphylococcus epidermidis as being a causative organism of CBP like acne of the prostate, which is a skin infection by Staphylococcus epidermidis. Now, it is generally believed that gram positive bacteria are also causative organisms as well as gram negative bacteria if the number of bacteria is greater in EPS or VB3 than that in VB 1 or VB $2^{11}$ (Fig. 1). 


\section{(3) NBP}

Diagnosis: Symptoms are various and usually mild in intensity but often long lasting. The method of localization used for diagnosis is similar to that used in CBP, but the number of leukocytes is examined instead of the bacterial count. Bacterial cultures of PF and/or BV 3 are negative. Some support the pathogenesis of Chlamydia trachomatis in NBP and some do not, and this dispute has not been settled for 20 years, during which time I established a method to identify Chlamydia trachomatis with urethral discharges from patients with urethritis as the first Japanese urologist in $1980^{16}$, but Chlamydia trachomatis was negative in all subjects with NBP in my study.

Treatment: Despite classification of this disease as nonbacterial, antibiotics have been traditionally used, because the pathogenesis of this disease is not

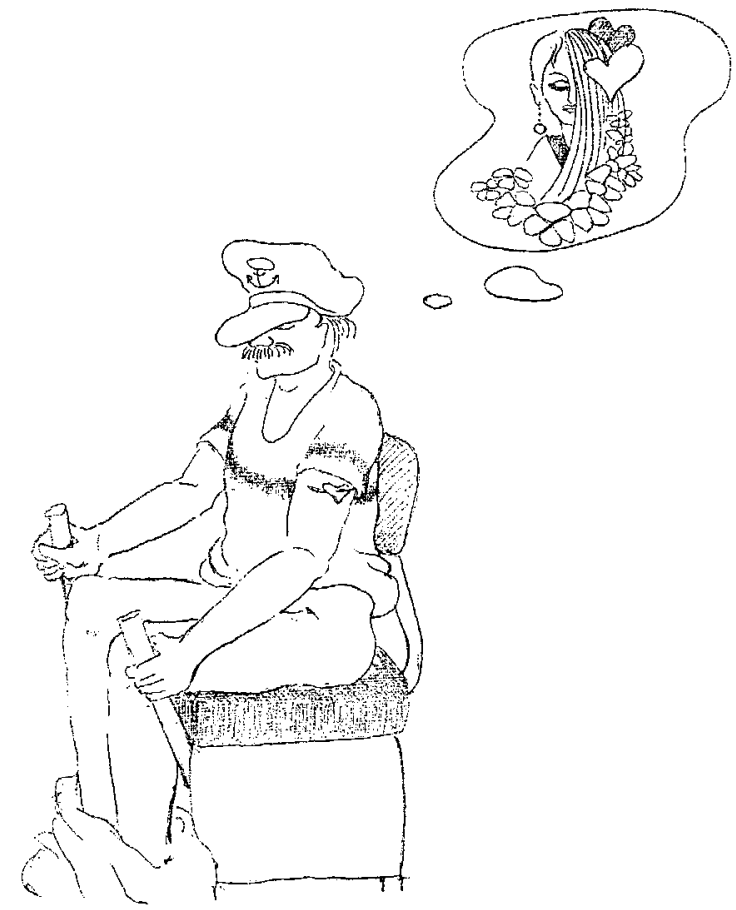

Fig. 2 Fisherman on automatic prostate massage machine known and bacteria undetected by routine cultures may be the cause. Other medications include antiinflammatory agents, $\alpha_{1}$ blockers, and Chinese medi cine. In intractable cases, transurethral or transrectal hyperthermia, transrectal ultrasound with simultaneous intrarectal instillation of steroids and antibiotic ointments, acupuncture, laser and automatic prostate massage machines ${ }^{17}$ (Fig. 2) are used, although the rate of effectiveness of these treatment is not satisfactory ${ }^{18}$. And these treat ments are also used in intractable cases of following prostatodynia (Table 5).

Significance of leukocytosis: Concerning the significance of leukocytosis, there have been several questions and problems as follows.

1) O'Shaughnessy et al. ${ }^{14}$ published a paper with an interesting title: "Chronic prostatitis-fact or fiction?" since they had found that three groups of males, normal men, those with a nonspecific urethral discharge and those referred with a diagnosis of chronic prostatitis, all showed the presence of a significant number of leukocytes in the prostatic fluid in a similar percentage. And there is a fluctuation in the number of leukocytes even in normal individuals, especially due to ejaculation ${ }^{19}$.

2) EPS obtained from leukocyte counts do not necessarily represent the inflamed lesion, because of the possibility of obstruction of the duct from the lesion $^{20}$.

To answer the forementioned questions, we have studied the macrophages in PF, detecting them by non-specific esterase staining ${ }^{21}$, and found many large macrophages which were intensely stained by nonspecific esterase staining in the early stage of acute prostatitis, while in chronic prostatitis there were only a few macrophages (Fig. 3) ${ }^{22}$. However, longitudinal study of the percentage of macrophages among leukocytes in PF from NBP patients in early convalescence did not necessarily show a correlation between clinical symptoms and the per-

Table 5 Various treatments for intractable cases of NBP or prostatodynia

Transurethral or transrectal hyperthermia

Transrectal ultrasound with simultaneous intrarectal instillation of steroid and antibiotic ointment

Acupuncture

Laser

Automatic prostate massage machine 

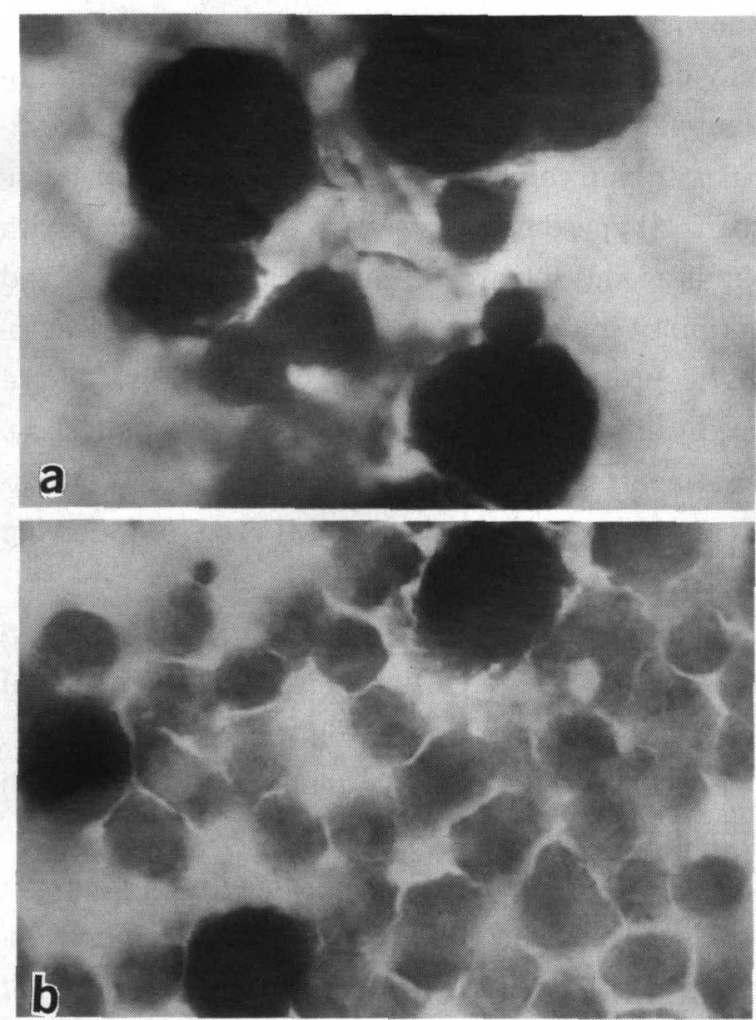

Fig. 3 There were many large macrophages which were intensely stained by nonspecific esterase staining in the early stage of acute prostatitis (a), while in chronic prostatitis only a few macrophages were observed (b)

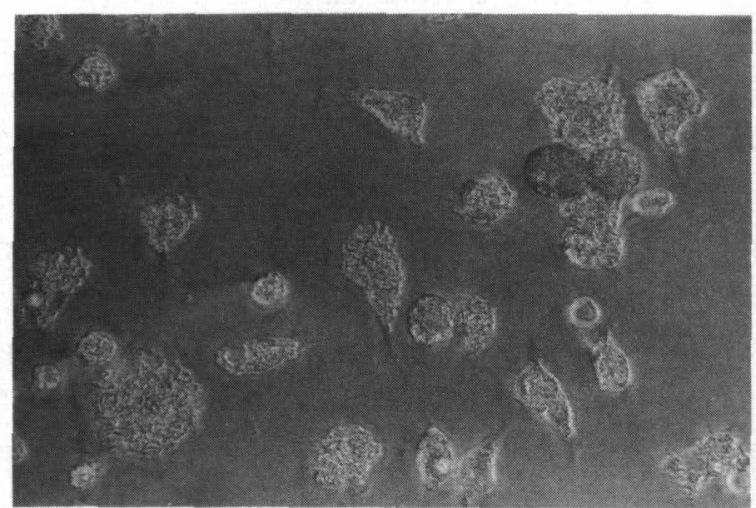

Fig. 4 Macrophages in the early stage of NBP were more activated' showing spreading on the bottom of the culture chamber

centages of macrophages or leukocyte count ${ }^{23}$. But it was found that macrophages in the early stage of NBP were more activated, showing spreading on the bottom of the culture chamber (Fig. 4), than macrophages in the chronic stage ${ }^{24}$. Most recently, we have attempted to clarify whether low levels of IL-1 ra vs. IL-1 are a cause of prostatitis prolongation. Recent papers have reported that the balance between the production of IL-1 and IL-1 ra probably influences the regulation of the host response and the severity and prolongation of inflammatory reaction in some disease $\mathrm{e}^{25}$ and that the balance is necessary for homeostasis of the mononuclear phagocytosis system ${ }^{26}$, because IL-1 ra limits the extent of the potentially deleterious effects of IL-1 $1^{27}$. However, our data revealed that low levels of IL-1 ra vs. IL-1 secreted in prostatic fluid are unlikely to be a cause of prolongation of NBP or prostatodynia ${ }^{28}$.

(4) Prostatodynia

Diagnosis: This word means "pain in the prostate"; symptoms are similar to those of NBP, but there is no abnormality of PF. A most important matter that clinicians should be aware of is that this category might include diseases without relation to the prostate such as detrusor-sphincter dyssynergia, tension myalgia of the pelvic floor or hemorrhoids.

Treatment: Because of the reasons mentioned above, $\alpha_{1}$ blockers or antispasmodics are effective in some cases.

(5) Granulomatous prostatitis

This has constituted only a small portion of cases of prostatitis; however, the frequency of this disease
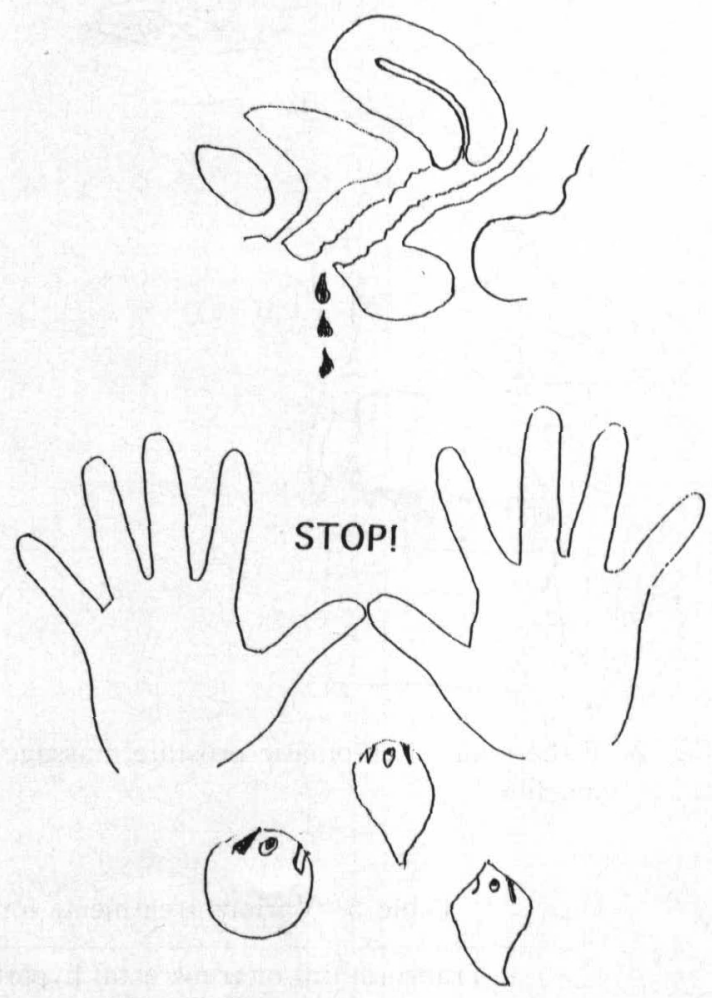

Macrophages in the prostate

Fig. 5 Sterile vaginal secretion during sexual intercourse may cause prostatitis by entering the prostate tissue and stimulating macrophages in the prostate 
has been increasing since intravesical instillation of $\mathrm{BCG}$, which causes granulomatous prostatitis, recently became a popular method of prophylaxis in superficial bladder cancer. This can be treated by transurethral resection of the prostate or antituberculosis medicines.

In conclusion, the etiology of $\mathrm{NBP}$ and prostatodynia, which constitute most cases of prostatitis, still remain, to be unveiled, and treatment of these groups is by no means easy. The author thinks there is a possibility that even sterile so called "love juice" which is a secretion from the vagina during sexual intercourse, may enter the prostate in retrograde fashion and stimulate macrophages in the prostate, which consequently destroy prostate tissue and cause an onset of prostatitis (Fig. 5). Anyway, it will take a long time to bring any benefit to patients with NBP or prostatodynia by clinical and experimental research.

\section{References}

1. Meares E: Prostatitis syndromes: New perspectives about old woe. J Urol 1980; 123: 141-147.

2. Drach GW, Nolan PE: Chronic bacterial prostatitis: Problems in diagnosis and therapy. Urology 1986; 27 (Suppl): 26-30.

3. Meares EM, Stamey TA: Bacteriologic localization patterns in bacterial prostatitis and urethritis. Inverst. Urol 1968; 5: 492-518.

4. Ghormely KO, Cook, ED, Needham GM: Bacterial flora in chronic prostatitis. Amer J Clin Path 1954; 24: 186-193.

5. Stahler H: Zur Behandlung unspezifischer Infection der hinteren Harnrohre und Prostata. A Urol 1955; 48: 285-295.

6. Guze LB, Beeson PB: Observations on the reliability and safety of bladder catheterization for bacteriologic study of the urine. New Eng J Med 1958; 259: 764-767.

7. Stamey TA, Fair WR, Timothy MM, Chung HD: Antibacterial nature of prostatic fluid. Nature 1968; 218: 444-447.

8. Stamey TA: Urinary infections in males. in Urinary infection. 1972; pp 161-212. Williams and Wilkins, Baltimore.

9. Katoh N, Ono Y, Oshima S, Miyake K: Diffusion of cefmenoxime and latamoxef into prostatic fluid in the patients with acute bacterial prostatitis. Urol Int 1992; 48: 1981-194.

10. Yamamoto M, Hibi H, Miyake K: Prostate-specific antigen levels in acute and chronic bacterial prostatitis. Acta Urol Jpn 1993; 39: 445-449.

11. Ikeuchi T, Kawamura N, Suzuki K, Onodera S, Osada T, Hirano A, Satomi Y, Yoshimura S, Yamamoto, Y: Clinical studies of Tosufloxacin on chronic bacterial prostatitis. Acta Urol Jpn 1993; 39: 673-678.

12. Gardner LWM: Bacteriology of chronic prostatoseminal vesiculitis. Urol Cutan Rev 1940; 44: 278-281.

13. O'Shaugnessy EJ, Parrino PS, White JD: Chronic prostatitis-face or fiction. JAMA 1956; 160: 540-542.

14. Schmidt JD, Patterson MC: Needle biopsy study of chronic prostatitis. J Urol 1966; 96: 519-533.

15. Drach GW: Prostatitis: Man's hidden infection. Urol Clin North Am 1975; 2: 499-520.

16. Nishimura $T$, Abe $H$, Yoshida $K$, Akimoto $M$, Konjiki T, Kawai H: Method of cultivation of Chlamydia trachomatis. Rinsho Hinyokika 1991; 35: 771-774.

17. Nishimura T, Horiuchi K, Oki M, Terashima $Y$, Sugizawa Y, Tsuboi N, Yoshida K, Akimoto M, Shi PC: Clinical application of transrectal ultrasonic therapy to nonbacterial prostatitis and prostatodynia cases which were resistant to conventional drug therapy. Acta Urol Jpn 1993; 39: 907-911.

18. Nishimura T: Prostatitis. Rinsho Hinyokika 1995; 49: 449-458.

19. Jameson RM: Sexual activity and the variations of the white cell content of prostatic secretion. Invest Urol 1967; 5: 297-302.

20. Blacklock NJ: Anatomical factors in prostatitis. $\mathrm{Br}$ J Urol 1974; 46: 47-54.

21. Nishimura T, Kanamori S. Akimoto M, Kawai H: Study of macrophages in prostatic fluid. I. Method for detection of macrophages. Jap J Urol 1981; 82: 785-789.

22. Nishimura T, Kanamori S, Akimoto M, Kawai H: Macrophages in prostatic fluid. Br J Urol 1980; 52: 381-385.

23. Nishimura T, Kanamori S, Yoshida K, Akimoto M, Kawai $\mathrm{H}$ : Longitudinal study of macrophages in prostatic fluid from nonbacterial prostatitis patients. Urology 1981; 18: 255-257.

24. Nishimura T, Terashima $Y$, Hattori T, Satoh M, Yoshida K, Akimoto M: Study of macrophages in prostatic fluid from nonbacterial prostatitis patients. V. Relation between activation of macrophages and stage of prostatitis. Urol Int 1991; 46: 15-17.

25. Nicoletti F, Patti F, Di Marco R, Zaccone P, Nicoletti A, Meroni PL, Reggio A: Circulating serum levels of IL-1 ra in patients with relapsing remitting multiple sclerosis are normal during 
remission phases but significantly increased either during exacerbations or in response to INF- $\beta$ treatment. Cytokine 1996; 8: 395-400.

26. Furukawa Y, Kikuchi J, Terui Y, Kitagawa S, Ohta M, Miura Y, Saito M: Preferential production of interleukin-1 $\beta$ over Interleukin-1 receptor antagonist contributes to proliferation and suppression of apoptosis in leukemic cells. Jpn J Cancer Res 1995; 86: 208-216.

27. Roberge CL, Poubelle PE, Beaulieu AD, Heitz D,
Gosselin J: The IL-1 and IL-1 receptor antagonist (IL-1 Ra) response of human neutrophils to EBV stimulation. J Immunol 1996; 156: 4884-4891.

28. Nishimura $T$, Abe $H$, Ito $H$, Ikeda $K$, Oka $F$, Yamamoto M: Low level of IL-1 ra versus IL-1 levels in prostatic fluid are not a cause of prolongation of prostatitis. J Nippon Med Sch 1996; 63: 502-503.

(Received, December 20, 1996) (Accepted for publication, December 26, 1996) 